\title{
The efficacy of delayed, repeated reduction enema in management of intussusception
}

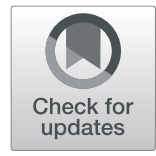

\author{
Tamer Fakhry, Ahmed Nabil Fawzy and Ahmed Taher Mahdy* (D)
}

\begin{abstract}
Background: Management of intussusception varies according to the case, time of presentation, cause, and symptoms. In this study, we focus on describing the demographic and sonographic characteristics of children with intussusception with failed initial enema reduction who were managed by delayed repeated enema attempts and identify predictors associated with successful repeated reduction.

Results: This study was conducted in the period from December 2018 to April 2020 at university hospitals (pediatric surgery unit). This study included 40 patients with intussusceptions; 27 are males, and 13 of them are females. Their ages ranged from 5 months to 3 years old. Patients in this study had failed initial enema reduction attempts under sonographic guidance and had subsequent delayed ( $\geq 2 \mathrm{~h}$ from the initial attempt) repeated enemas made up the study population.

Of the 40 patients, 34 patients (85\%) were successfully reduced, and 6 patients (15\%) failed reduction and required surgical intervention. There were no deaths, perforation, or resection of gangrenous bowel. Two cases showed recurrences, but required no surgical intervention. It is also noted that early presentation $(<12$ h), stable, noncomplicated, and with little or no bloody diarrhea are predictors of successful DRE.

Conclusion: Delayed repeated enema in the treatment of intussusception is a viable option in patients with unsuccessful initial enema reduction provided that early presentation, stable vitals, and no signs of perforation or peritonitis are present.
\end{abstract}

Keywords: Delayed enema, Intussusception, Non-surgical treatment

\section{Background}

The non-operative reduction of intussusception is the standard of care nowadays. It has been a subject of great debate for many radiologists, as they continue to modify techniques for increasing the chance of successful reduction and reduce the amount of radiation exposure [1].

Non-operative reduction methods for intussusception include contrast enema and hydrostatic or pneumatic reduction [2]. U/S hydrostatic reduction is currently the first line of treatment, given the easiness in performing the examination, less morbidity, and high success rate reaching up to $84-100 \%$ [3]. The operative reduction is required when hydrostatic reduction is either

* Correspondence: a01062580870@gmail.com

Pediatric Surgery Unit, General Surgery Department, Faculty of Medicine, Menoufia University, Menofia, Egypt

\section{Springer Open}

unsuccessful or contraindicated (e.g., peritonitis, perforation, profound shock).

Open surgery has been the usual approach although laparoscopic reduction is also easy and successful in uncomplicated cases [4].

Many patients who failed initial enema reduction were taken for immediate surgery due to concern of ischemia in unreduced intussusception. Delayed, repeated reduction enemas have been reported by many groups, who describe a period of waiting ranging from $30 \mathrm{~min}$ to $12 \mathrm{~h}$ before trying DRE for unsuccessful initial reduction attempt. DRE shows further increase in non-operative reduction by $50-60 \%[5]$.

Our aim in this study is to describe the sonographic and demographic features of children with intussusception with failed initial enema reduction who were 
managed by delayed repeated reduction attempts and to identify predictors associated with successful repeated reduction.

\section{Methods}

This study was conducted in the period from December 2018 to April 2020 at university hospitals (pediatric surgery unit), and it included 40 patients with intussusception who had failed initial enema reduction attempts under sonographic guidance. Patients in this study had failed initial enema reduction attempts under sonographic guidance and had subsequent delayed $(\geq 2 \mathrm{~h}$ from the initial attempt) repeat enemas which made up the study population.

This study was approved by the ethical committee of the faculty of medicine. Also, publishing permission and consent were taken from the parents.

All patients were subjected to history taking, clinical examination, laboratory investigations, abdominal U/S, and enema reduction under sonographic guidance. $\mathrm{Pa}-$ tients included in the study were as follows: children between the age of 5 months and 3 years. Also, cases with little or no bloody diarrhea and early stable cases with neither signs of perforation, shock, nor peritonitis were included. Patients excluded from the study were as follows: cases present with perforation, peritonitis, shock, or dehydration. Before reduction enema is done, initial resuscitation of the patient with IV fluids and a dose of antibiotic was given. Fluid was prepared for reduction [saline: ULTRAVIST (Iopromide)] by a ratio of $(2: 1)$ at a temperature of 37.5-the same as body temperature. Foley catheter was inserted transanally into the rectum and balloon inflated. Two hundred to $250 \mathrm{ml}$ of solution was injected through a catheter with careful and steady pressure under ultrasonographic guidance. If U/S-guided reduction failed, after $15 \mathrm{~min}$, plain abdominal $\mathrm{x}$-ray is done to show if it is residual intussusception or not (Fig. 1). Another trial was taken after $1-2 \mathrm{~h}$ using 200 to 250 $\mathrm{ml}$ of the solution under U/S guidance if $\mathrm{U} / \mathrm{S}$ shows persistent intussusception. Repeated trials can be carried out with intervening plain $\mathrm{x}$ - rays to prove a success as long as the patient is stable with no signs of peritonitis and perforation until the complete reduction of intussusception or flow of dye into intestine on $\mathrm{x}$-ray or $\mathrm{U} / \mathrm{S}$ (Fig. 2). As long as the patient is stable and there is no development of peritonitis, continue trials.

For a patient with failed repeated enema reduction, laparotomy is done with transverse right-sided supraumbilical incision, reduction of intussusception, and appendectomy. Lymphadenectomy may be done in cases of huge lymph nodes that make the risk of recurrence high.

\section{Results}

A total of 40 patients with intussusception who failed initial enema reduction were identified. Aged from 6 months to 3 years, 27 of 40 patients $(67.5 \%)$ were males and 13 of $40(32.5 \%)$ were females. Patients presented with most common manifestations, abdominal pain (90\%), vomiting (85\%), red currant jelly stool (62.5\%), and mass felt in the abdomen $(20 \%)$ of the patients. Patients who presented with the classic triad of pain, mass, and red currant jelly stool represent only $20 \%$ of cases (Tables 1 and 2).

Patients were divided according to the duration of symptoms into 3 groups: 8 of $40(20 \%)$ of patients presented between 6 and $12 \mathrm{~h}$ of symptoms, 26 of 40 (65\%)

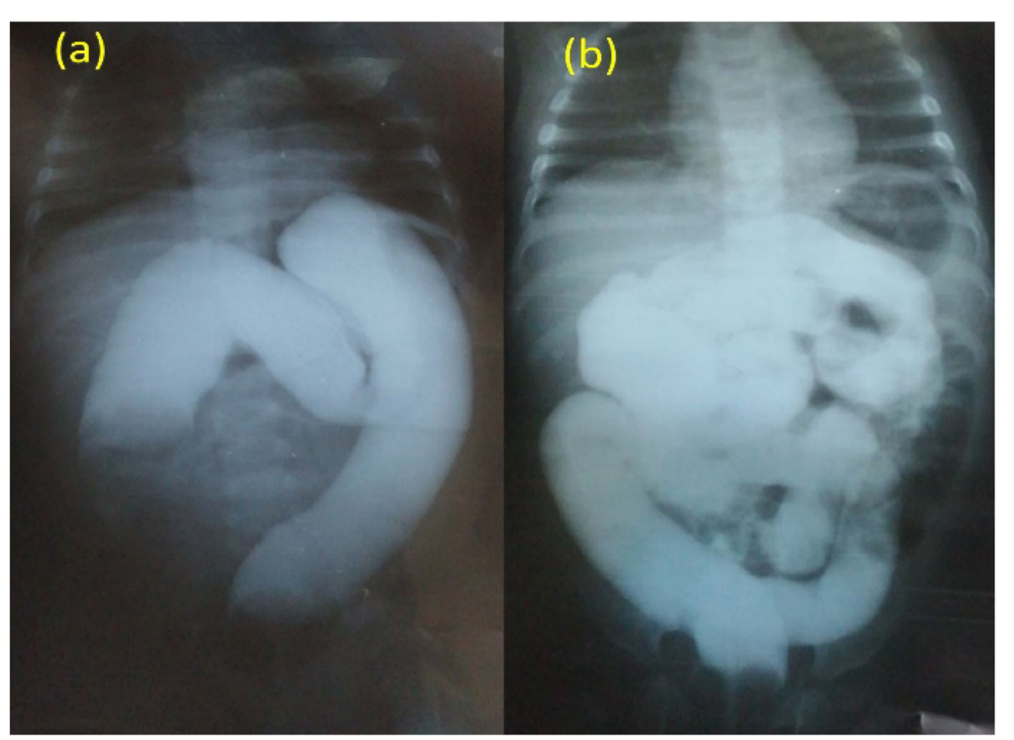

Fig. 1 Contrast study of abdomen (contrast enema). a Partial reduction of intussusception. b Complete reduction of intussusception 

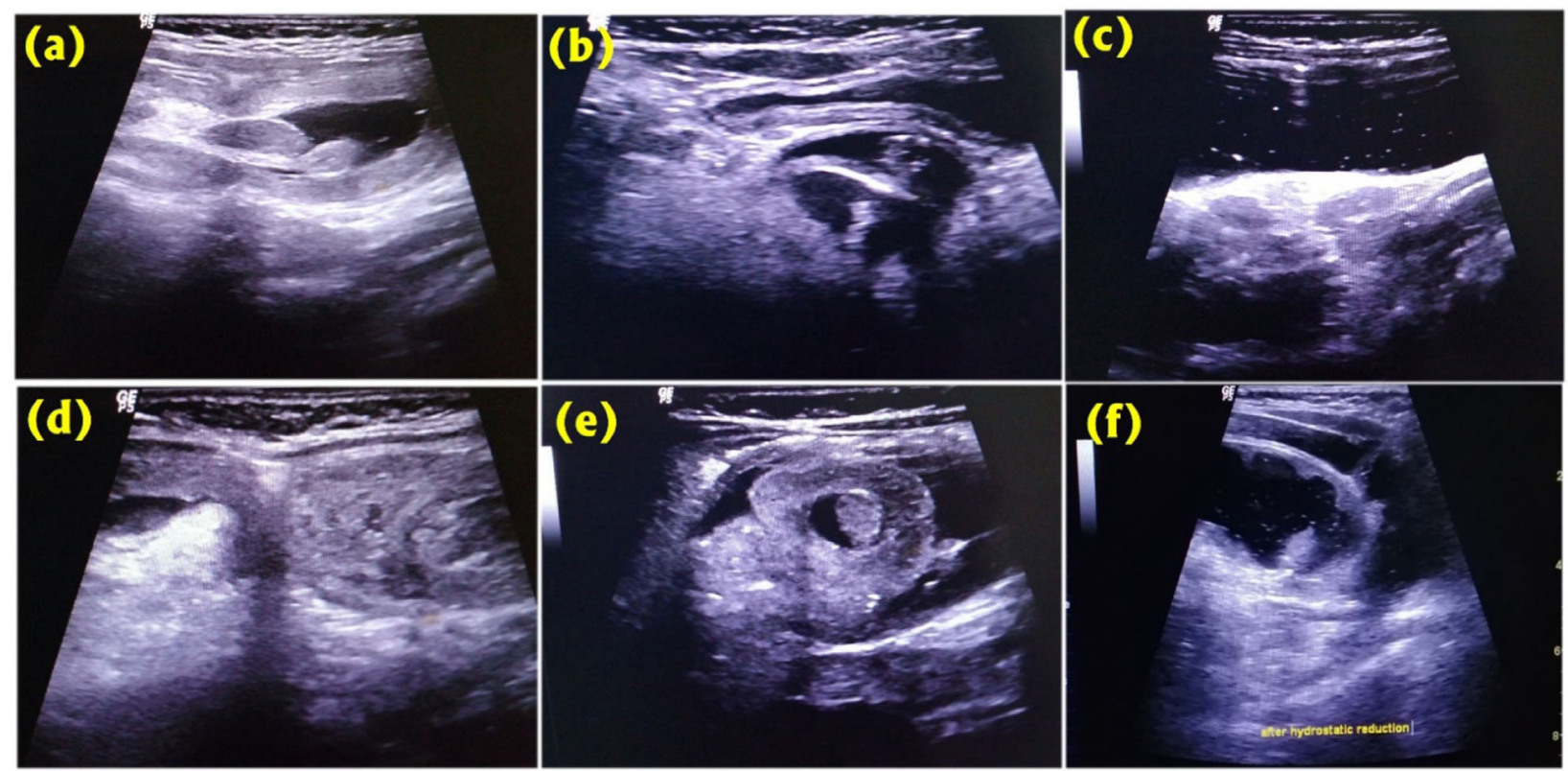

Fig. 2 U/S pictures showing different levels of reduction using saline enema for reduction of intussusception. $\mathbf{a}$, b Enema solution start to push through bowel loops. c Flow of solution through bowel loops. d Fluid pushing intussusceptum. e Fluid enter in between intussusceptum and intussuscipiens at ileocecal junction. $\mathbf{f}$ Complete resolution of intussusception and fluid reaching small bowel

presented $12-24 \mathrm{~h}$ of symptoms, and 6 of 40 (15\%) presented more than $24 \mathrm{~h}$ of symptoms onset. We found that patients who presented $<24 \mathrm{~h}$ has a higher chance for successful delayed enema than those presented $>24$ h with $(P$ value $=0.03)($ Tables 2 and 3$)$. Thirty-four of $40(85 \%)$ have successful delayed enema, while 6 of 40 (15\%) required surgical intervention. Twenty of 34 (59\%) reduced from the 2 nd trial, 10 of 34 (29\%) reduced from

Table 1 Incidence of intussusception according to sex, age, and symptoms

\begin{tabular}{ll}
\hline Parameters & No. of patients \\
\hline Sex & \\
Male & $27(67.5 \%)$ \\
Female & $13(32.5 \%)$ \\
Total & $40(100 \%)$ \\
Age & \\
6 months-1 year & $23(57.5 \%)$ \\
$1-2$ years & $9(22.5 \%)$ \\
$>2$ years & $8(20 \%)$ \\
Total & $40(100 \%)$ \\
Symptoms & \\
Bloody stool & $25(62.5 \%)$ \\
Pain & $38(90 \%)$ \\
Mass & $22(55 \%)$ \\
Vomiting & $34(85 \%)$ \\
Classic triad & $8(20 \%)$ \\
\hline
\end{tabular}

the 3rd trial, and 4 of 34 (12\%) reduced from the 4 th trial with reduction time ranging from $30-270 \mathrm{~min}$.

Of 6 patients who required surgical intervention, 2 patients required manual reduction, 2 patients had pathological lead points, one patient who was 3 years old had appendicectomy for inflamed appendix which turned to be catarrhal appendicitis with fecolith inside, and another one who was 2 years old required lymphadenectomy for huge lymph nodes which turned to be nonspecific lymphadenitis. Two patients on surgical exploration were found completely reduced. There were no deaths, no perforation, and no resection of gangrenous bowel. Two patients presented with recurrences that required no surgical interventions (Table 4).

\section{Discussion}

The age of the patients in this study ranged from 6 months to 3 years, $60 \%$ below 1 year of age, and $90 \%$ below 2 years of age. There is statistically no significant difference in age between patients who have successful repeated reduction attempts and those who failed. This finding is in agreement with Gorenstein et al. [6].

Among the 40 patients of this study, there were 25 males and 15 females; the disease is commoner in males, but there is no statistical significance that age affects the results of successful repeated reduction attempts. In our study, red currant jelly stool was not a contraindication for enema reduction; it presented in 25 patients (62.5\%). Twenty-one of them had a successful delayed repeated enema and 4 failed; this is not statistically significant. 
Table 2 Effect of different variables on outcome

\begin{tabular}{|c|c|c|c|c|c|c|}
\hline \multirow[t]{3}{*}{ Variables } & \multicolumn{4}{|c|}{ Outcome } & \multirow[t]{3}{*}{$x^{2}$} & \multirow{3}{*}{$\begin{array}{l}P \\
\text { value }\end{array}$} \\
\hline & \multicolumn{2}{|c|}{ Failed } & \multicolumn{2}{|c|}{ Recovered } & & \\
\hline & No & $\%$ & No & $\%$ & & \\
\hline \multicolumn{7}{|l|}{ Age } \\
\hline From 6 months to less than 1 year & 3 & 50 & 20 & 58.8 & 0.47 & 0.788 \\
\hline From 1 year to less than 2 years & 2 & 33.3 & 7 & 20.5 & & \\
\hline $2-3$ years & 1 & 16.7 & 7 & 20.5 & & \\
\hline \multicolumn{7}{|l|}{ Gender } \\
\hline Male & 3 & 50 & 24 & 70.5 & 0.98 & 0.32 \\
\hline Female & 3 & 50 & 10 & 29.5 & & \\
\hline \multicolumn{7}{|l|}{ Classic triad } \\
\hline Yes & 3 & 50 & 5 & 14.8 & 3.9 & $0.04^{*}$ \\
\hline No & 3 & 50 & 29 & 83.3 & & \\
\hline \multicolumn{7}{|l|}{ Red currant jelly } \\
\hline Yes & 4 & 66.7 & 21 & 61.7 & 1.6 & 0.19 \\
\hline No & 2 & 33.3 & 13 & 38.3 & & \\
\hline \multicolumn{7}{|l|}{ Duration of symptoms } \\
\hline From 6 to less than $12 \mathrm{~h}$ & 1 & 16.7 & 7 & 20.5 & 6.8 & $0.03^{*}$ \\
\hline From 12 to less than $24 \mathrm{~h}$ & 2 & 33.3 & 24 & 70.5 & & \\
\hline More than $24 \mathrm{~h}$ & 3 & 50.0 & 3 & 9.0 & & \\
\hline
\end{tabular}

*Significant

This finding is in agreement with Gorenstein et al. and in disagreement with McDermott et al. who wrote that rectal bleeding is more likely to cause failed delayed repeated enema [6, 7].

In our study, patients who presented with the classic triad of symptoms (pain, red currant jelly stool, and mass) were 8 patients: 5 showed successful delayed repeated enema (DRE) and 3 failed (DRE), which represents $50 \%$ of failed cases. This is statistically significant and means that patients who presented with a combined classic triad of Symptoms are more liable to surgical intervention than those without. This finding is in agreement with Simon et al. [8].

In our study, we used U/S as the main radiological investigation to diagnose and help in the reduction of intussusception; erect $\mathrm{x}$-rays on the abdomen showed little or no information to help in the diagnosis of intussusception. This finding is in agreement with Simon et al. [8]. In our study, we used saline enema with water-

Table 3 Duration of symptoms before hospital admission

\begin{tabular}{ll}
\hline Duration of symptoms & No. of patients \\
\hline From 6 to $12 \mathrm{~h}$ & $8(20 \%)$ \\
From 12 to $24 \mathrm{~h}$ & $26(65 \%)$ \\
$>24 \mathrm{~h}$ & $6(15 \%)$ \\
Total & $40(100 \%)$ \\
\hline
\end{tabular}

soluble contrast in a ratio of 2:1 respectively in performing DRE, under sonographic guidance, and without the use of general anesthesia. A plain erect abdominal $x$-ray was done in between reduction attempts in order to confirm the level of reduction and use of hygroscopic properties of the contrast to reduce edema at the ileocecal junction. Also, there is no enough evidence, but we found 2 failed cases completely reduced on laparotomy. Symptom duration before the diagnosis is a very important factor in the prediction of successful reduction. In our study, 8 patients who presented with symptoms since $6-12 \mathrm{~h}$ showed an $87.5 \%$ success rate, 26 patients who presented with symptoms since $12-24 \mathrm{~h}$ showed a

Table 4 The outcome of delayed repeated enema

\begin{tabular}{ll}
\hline Outcome & No. of patients \\
\hline Response & \\
Recovered & $34(85 \%)$ \\
Failed & $6(15 \%)$ \\
Surgical intervention & $6(15 \%)$ \\
Recurrence & $2(5 \%)$ \\
Pathological lead points & $2(5 \%)$ \\
Mortality rate & \\
Alive & $40(100 \%)$ \\
Dead & $0(0.0 \%)$ \\
\hline
\end{tabular}


92.3\% success rate, and patients who presented with symptoms more than $24 \mathrm{~h}$ showed $50 \%$ success rate. This is statistically significant and means that symptoms which started more than $24 \mathrm{~h}$ have a $50 \%$ failure rate; this finding is in agreement with Vujovic et al. [9]. But this proves that even patients with a longer time of symptoms have a $50 \%$ success rate as long as they are vitally stable with no signs of peritonitis. In our study, we had a recurrence of 2 cases (about 5\%) subjected to delayed repeated enema with no recurrence in cases subjected to surgical intervention; also, our numbers are better, but this finding is in agreement with Simon et al. [8]. Also, in our study, there were 4 patients who have successful enema on the 4th attempt of delayed repeated enema. Also, there were 6 patients subjected to surgical intervention after 4 attempts of delayed repeated enema. Among 6 patients with surgical intervention, 2 were found completely reduced on surgical exploration. Also, 2 patients have recurrences who required no surgical intervention. This proves that there is no absolute contraindication for conservative treatment or the number of trials as long as the patient is vitally stable and shows no signs of perforation or peritonitis. This finding is in agreement with Simon et al. [8].

Although factors such as prolonged length of illness, rectal bleeding, altered mental status, and cases with classic triad (pain, vomiting, and bloody diarrhea) have been found to be associated with an increase rate of failed enema reduction, these factors alone are not contraindications to delayed repeat enema management.

This study was limited by the small number of cases included, and our main focus was on early noncomplicated cases.

\section{Conclusion}

Intussusception is considered the leading cause of abdominal surgical emergencies in children younger than 5 years. Delayed repeated enema in the treatment of intussusception is a viable option in patients with unsuccessful initial enema reduction and in reducing the number of laparotomies and its complications. There is no specific number of trials for delayed enema as long as the patient is stable with no signs of perforation or peritonitis.

\section{Abbreviations}

U/S: Ultrasound; DRE: Delayed repeated enema; No: Number

\section{Acknowledgements}

Not applicable.

\section{Authors' contributions}

TF made the study design. TF is the senior operating surgeon; AM and AN are assistants. Data collection and case follow-up was done by AM. AM wrote the first draft of manuscript; TF and AN revised the first draft into final manuscript. All authors have agreed to authorship and order of authorship. All authors have read and approved the manuscript.
Funding

None exists

\section{Availability of data and materials}

The data used in the current study are available from the corresponding author on reasonable request.

\section{Ethics approval and consent to participate}

This study was approved by the surgery department and ethics committee of faculty of medicine, Menofia University. Reference number is not available. A written consent was obtained from a parent or guardian of the patients.

\section{Consent for publication}

Informed verbal as well as written consent for publication of the data have been obtained from the parents of the patients included in this study as per the institution's rule.

\section{Competing interests}

The authors declare that they have no competing interests.

Received: 11 August 2020 Accepted: 28 January 2021

Published online: 25 February 2021

References

1. Naiditch J, Rigsby C, Chin A. Delayed repeated enema and operative findings after unsuccessful primary enema for intussusception. Eur J Pediatr Surg. 2012;22(05):404-8.

2. Waseem M, Rosenberg H. Intussusception. Pediatr Emerg Care. 2008;24(11): 793-800.

3. Bines J, Ivanoff B, Justice F, Mulholland K. Clinical case definition for the diagnosis of acute intussusception. J Pediatr Gastroenterol Nutr. 2004;39(5): 511-8.

4. Pazo A, Hill J, Losek J. Delayed repeat enema in the management of intussusception. Pediatr Emerg Care. 2010;26(9):640-5.

5. Navarro O, Daneman A, Chae A. Intussusception: the use of delayed, repeated reduction attempts and the management of intussusceptions due to pathologic lead points in pediatric patients. Am J Roentgenol. 2004; 182(5):1169-76.

6. Gorenstein A, Raucher A, Serour F, Witzling M, Katz R. Intussusception in children: reduction with repeated, delayed air enema. Radiology. 1998; 206(3):721-4.

7. McDermott V, Taylor T, Mackenzie S, Hendry G. Pneumatic reduction of intussusception: clinical experience and factors affecting outcome. Clin Radiol. 1994:49(1):30-4.

8. Simon N, Joseph J, Philip R, Sukumaran T, Philip R. Intussusception: single center experience of 10 years. Indian Pediatr. 2019;56(1):29-32.

9. Vujovic D, Lukac M, Sretenovic A, Krstajic T, Ljubic V, Sindjic-Antunovic S. Indications for repeated enema reduction of intussusception in children. Srp Arh Celok Lek. 2014;142(5-6):320-4.

\section{Publisher's Note}

Springer Nature remains neutral with regard to jurisdictional claims in published maps and institutional affiliations.

\section{Submit your manuscript to a SpringerOpen ${ }^{\circ}$ journal and benefit from:}

- Convenient online submission

- Rigorous peer review

- Open access: articles freely available online

High visibility within the field

- Retaining the copyright to your article

Submit your next manuscript at $>$ springeropen.com 